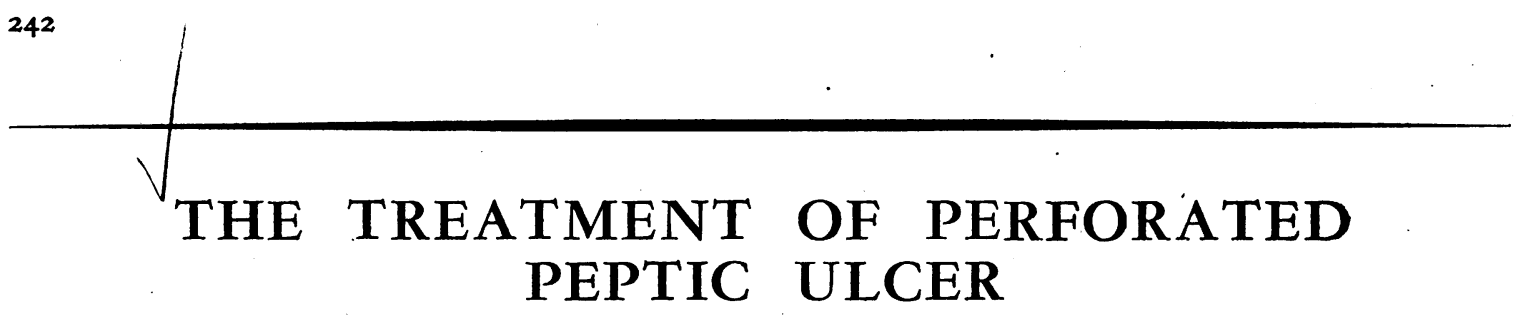

By F. Austin Henley, M.B., B.S., F.R.C.S.

Consultant Surgeon to the Central Middlesex Hospital

No greater catastrophe can happen to a patient with a peptic ulcer than perforation.

The two most important factors are the mortality and the morbidity which result from treatment. The concern of every surgeon is to elect the correct treatment for each individual case.

\section{Mortality}

It is agrced by all authorities that the decline in the mortality is due to the introduction of the antibiotics, the restoration of fluid and electrolyte balance, and the availability of good anaesthesia. Avery Jones et al. (1950) showed a diminishing death rate frcm 12 in 39 cases in 1938 , to 1 in 54 in 1948. Each intervening year revealed a steady improvement. The overall mortality was 96 deaths in 490 cases ( 19.6 per cent.) with $4 \mathrm{I}$ deaths in 117 perforated gastric ulcers (35 per cent.). Forty (1946) quotes a mortality figure of 42 per cent. for perforated gastric ulcers, whilst that quoted by other authors range from 5.6 per cent. for short series of cases to 25 per cent. in the bigger series. At the Utrecht University Hospital the mortality before 1920 was 43 per cent., between 1920 and 1930 it was 28 per cent., and from 1930 to 1934 it was 22 per cent. Chamberlain (195I) gave a mortality of 17.94 per cent. following simple suture in 1,622 perforations, covering the years 1930 to 1949. The other factors influencing the mortality are well recognized; for example, the time interval between the onset of the perforation and the commencement of treatment, the age of the patient, the enthusiastic and adequate post-operative treatment of the chest, and the seniority of the surgeon and anaesthetist. In one series (Gilmore, 1953) 80 per cent. of the patients were operated upon in less than 12 hours after perforation with a mortality of 3 per cent. With a delay of $12-24$ hours the mortality rose to 18 per cent., and over 24 hours it became 40 per cent. Such figures are in accordance with the generally accepted fact that delay in surgery leads to an increased mortality.

With regard to age of the patient the mortality below 40 years of age is I per cent. or less in the best hands, but over the age of 60 figures up to 20 per cent. are not uncommon. An interesting observation was made by Gilmore (1953) that in II9 patients with perforated acute ulcers there were no deaths, but in 87 perforated chronic ulcers 13 patients died, a mortality of $I_{5}$ per cent. As all these patients were treated by simple suture of the perforated ulcer the cause of death must be due to one of the following factors: (I) Chronic ill-health before perforation due to malnutrition; (2) pyloric stenosis with vomiting and consequent fluid and electrolyte imbalance; (3) continued pyloric stenosis following suture; (4) chronic pulmonary disease exacerbated by the absorption of purulent material from the abdomen; (5) bleeding consequent upon suture at the ulcer site; (6) failure to secure obliteration of the perforation because of immobility of the area; and (7) bleeding from another unrecognized ulcer.

There is, therefore, still a threatening mortality following simple suture in the treatment of a perforated peptic ulcer, and the perforated gastric ulcer appears to be consistently more lethal than the perforated duodenal ulcer.

\section{Morbidity}

Illingworth (1946) wrote that the longer the history of peptic ulcer before perforation and the sooner the recurrence of post-operative symptoms the worse was the prognosis.

In Forty's (1946) series 25 per cent. had recurrence of symptoms in the first year and 38 per cent. recurred over the first five years. In accordance with Illingworth's dictum 17 per cent. recurred in those with a three-year history or less, 25.7 per cent. in those with a three to five-year history, 32 per cent. in those with a five to tenyear history, and 40 per cent. in patients with a ten-year or more pre-operative history.

Lassen (1952) found that 38 per cent. of his patients developed severe ulcer symptoms postoperatively and that only 20 per cent. remained symptom-free. Eight other Scandinavian authors quoted by Lassen maintained that 42 . per cent. developed severe symptoms of recurrent ulcer 
post-operatively and another 28 per cent. had symptoms of a moderate degree. In Turner's (195I) review of 143 patients, 122 experienced peptic ulcer symptoms post-operatively following simple suture, i.e. 85.4 per cent. These symptoms were severe in 77.5 per cent., of which 38.5 per cent. underwent further surgery. In Chamberlain's (I95I) follow-up of 1,622 patients, of which only 56 per cent. were traced, 4 per cent. had recurrent perforation, I4 per cent. underwent further surgery, 33 per cent. had symptoms sufficient to seek medical advice and treatment, and 2 per cent. died of their ulcer. In all, 53 per cent. were unrelieved of their peptic ulcer symptoms following simple suture of the perforation.

In a study of the late results following perforated gastric and duodenal ulcers Doll (1950) found that after two years 63 per cent. of the perforated gastric ulcer were unsatisfactory. Some patients had died from their ulcer, some developed carcinoma of the stomach, some were readmitted to hospital for further surgical or medical treatment, and others had recurrence of ulcer pain and dyspepsia. Of the duodenal ulcers 53 per cent. were similarly affected. He further stated that between two and twelve years following simple suture of a perforation the gastric ulcer figure became 67 per cent. and that of the duodenal ulcer 60 per cent. In one series he traced 68 patients who had had perforated gastric ulcers, and of these 8 ( 12 per cent.) had developed carcinoma of the stomach.

It therefore appears from the literature that only one out of every five patients treated by simple suture of a perforation remains symptomfree, and that two out of every five are sufficiently troubled by the disease to necessitate further treatment. The possibility of carcinoma of the stomach should be taken into consideration in the treatment of a perforated gastric ulcer.

\section{Treatment}

The treatment of the perforated peptic ulcer is surgery.

\section{Non-operative Treatment}

Where for medical reasons surgery is prohibited or the patient refuses an operation, conservative treatment should be instituted. The liability of conservative measures under any other circumstances places a grave responsibility on the medical attendants both to accuracy of diagnosis and prognosis. Wangenstein (1935) first advocated continuous intragastric decompression for localized duodenal perforation. Its use, however, has been recorded with varying mortality: 47.5 per cent. mortality in 67 patients by Olsen and Norgore (1946), 21.3 per cent. by the late Hedley Visick in 14 cases (1946), and in the same year Taylor气 lost I 4 per cent. of 28 patients. An average? figure of 8 per cent. is given for ${ }_{3} 8$ cases (Ivy, $\stackrel{\varnothing}{\complement}$ Grossman and Bachrach). Are the results ob-.. tained in other clinics too prohibitive to record ? $\vec{F}$

The procedure in the non-operative treatment is gastric decompression by continuous suction through a Ryle's tube, with the administration of $\frac{\bar{c}}{\bar{w}}$ parenteral fluid and electrolytes and an accurate $\frac{\vec{\sigma}}{\sigma}$ fluid balance record. Antibiotic therapy should $\stackrel{\mathbb{}}{\circ}$ be started at the same time whilst pain and gastro- $\infty$ intestinal spasm are relieved by morphia and other $\vec{O}$ analgesics and antispasmodics. In the perforation of an acute ulcer spasm might assist the $\vec{\omega}$ sealing off of the ulcer, but with adequate intra- $\frac{\sigma}{0}$ gastric decompression the relief of pain and the $\frac{0}{3}$ comfort of the patient are of paramount import- $\frac{3}{\omega}$. ance. These measures are maintained for seventy $\vec{\omega}$ two hours when feeding by mouth is commenced along the same lines as in post-operative gastric on surgery. Subsequent treatment will depend upon $\frac{N}{\mathrm{~N}}$ the clinical improvement or otherwise in the patient's condition.

\section{Operative Treatment}

Surgical treatment has passed through several very definite stages in keeping with the advanc $\&$ o ment in anaesthesia.

Simple closure of a perforation was the origin surgical method of choice and is still the most universally used procedure. This was followed by suture and gastro-jejunostomy. Stomal ulceration followed rapidly in its wake, and this complication dreaded by both patient and surgeon alike, $\overrightarrow{\overrightarrow{\vec{A}}}$ and described by Sir Gordon Gordon-Taylor as $\frac{3}{3}$ the worst malady ever invented by the surgeon, led the operation into disrepute, and in England for all practical purposes it is abandoned. Excision of the ulcer with suture of the perforation has its advocates, but the end-result is similar to that of simple suture.

Keetley of London in 1902 did the first partial gastrectomy for a perforated ulcer. It had been advocated by several continental surgeons before 0 1930, including Von Haberer (1919), Duval, Schmieden and in 1933 by Noordenbos. More 을. recently Lowden (1952) reported $5 \mathrm{I}$ cases of perforated peptic ulcer treated by primary partial $N$ gastrectomy without mortality. Mention must N be made of Youdine of Moscow (1939), who N reported $I, 400$ cases.

The arguments against primary partial gastrectomy as the operation of choice are:

I. The ulcer may be acute with little or no history, and therefore medical treatment has not been given a trial. Nuboer (195I) stated that an acute ulcer never perforates and that all the ulcers removed by him were subjected to histological 


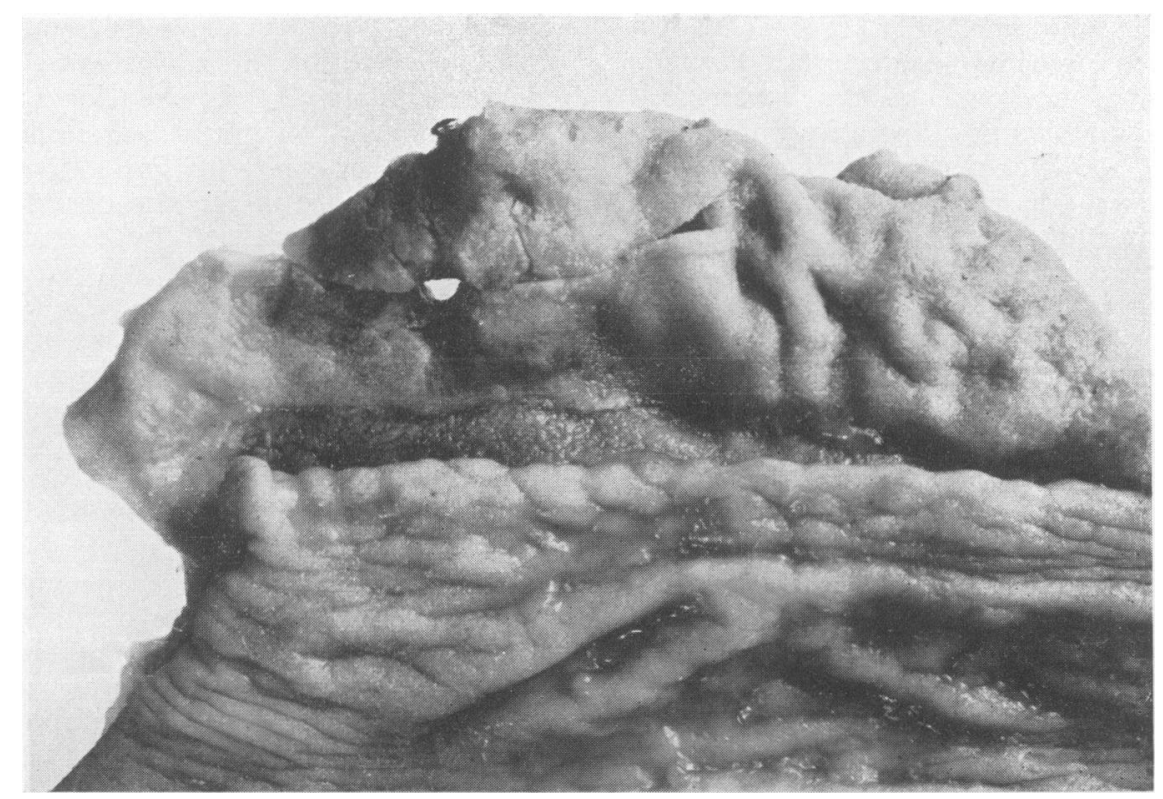

FIG. 1.-Illustrates a small duodenal ulcer perforation in a girl aged 17. Although there was no history of indigestion or medical treatment, this illustrates Gilmore's point that a chronic ulcer is not always attended by symptoms.

examination and shown to be chronic with considerable changes in the submucosa and deeper layers. Emmett also stated that the absence of prolonged ulcer symptoms in certain perforated ulcer patients is no indication of a benign lesion.

2. Thirty per cent. of patients are free from symptoms following simple suture. Therefore, primary gastrectomy is unnecessary in 30 out of every 100 patients. In the other 70 per cent. radical operation is indicated and one operation to cure one disease is better than the risk of two anaesthetics, two operations and the economical loss by the patient, his medical attendants and the State through bed-occupancy.

3. In these days of adverse criticisms of the doctor-patient relationship, the patient after suture for his perforation is most grateful, but when he learns he may have to undergo a second operation the news is a shock to his morale. When readmitted to the ward for gastrectomy he is a comparatively fit man and the morning after operation is acutely aware of his many discomforts. Further, his chances of developing an incisional hernia are doubled.

4. It may be stated that one should treat the peritonitis and the perforation and not the ulcer. Is it not more profitable to treat the cause of the ulcer and thereby the cause of the peritonitis and by so doing prevent the need for further surgery? The mortality from primary gastrectomy is less than for simple suture, provided a good surgical team is at hand. Bisgard 2.7 per cent. ( 1 in 36 ) Lowden no mortality in $5 \mathrm{I}$ cases, Henley no mortality in 12 cases, DeBakey less than 2 per cent. ( $\mathrm{I}$ in 55), and Mathewson no mortality in 5 cases. A perforated ulcer following simple suture may bleed, in which case the mortality is 50 per cent. Partial gastrectomy will prevent this complication.

5. In the presence of a soiled peritoneum a partial gastrectomy does seem a major undertaking, but the operation is no more difficult technically, and if the peritonitis is going to produce a chest complication post-operatively, as it is so prone to do, the choice of operative procedure will have little effect. A routine gastrectomy in the presence of adhesions around the duodenum, and perhaps undertaken as an emergency for pyloric stenosis, is more liable to damage the common bile duct than one in which oedema has separated the tissues, with an anterior ulcer.

6 . There may be more than one ulcer present and the writer recalls an instance where the duodenal perforation was oversewn in an elderly patient, to be followed ten days later by a massive intestinal haemorrhage from which the patient died within four minutes. Autopsy revealed a gastric ulcer four inches in diameter penetrating the pancreas just on the proximal side of the pylorus. Partial gastrectomy may have saved this patient.

7. The final argument is what to do with the 


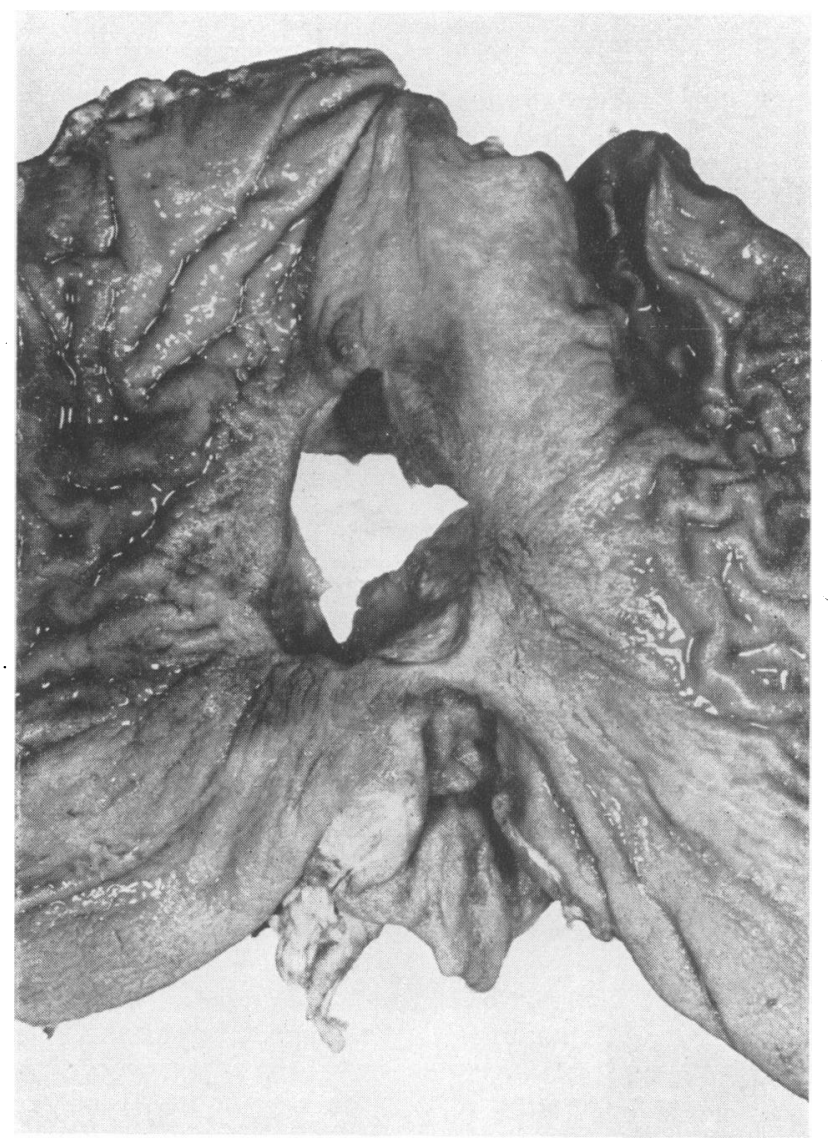

Fig. 2.-This illustration demonstrates the craggy irregularity of a perforated gastric ulcer in a man aged 59.

patient under the age of 20 who presents with a perforation. If it could be ascertained that this was merely a single incident in the life of the patient, simple suture would be adequate, but if on the other hand this patient is doomed to lead a life of frequent medical and hospital attendances, to swallow large quantities of alkalis and other medicines, and maybe to receive surgery in later years, then partial gastrectomy would undoubtedly be the correct treatment of the initial lesion (Fig. I).

Between August 195I and August 1954, seventy five perforated peptic ulcers were admitted to my unit. Twenty-two underwent primary partial gastrectomy, fourteen had jejunal replacement with one death (from a pelvic abscess), and the remaining eight had a Billroth I operation with one death. Thirty-six underwent simple suture of the perforation with two deaths: one was moribund on ad- mission and the other died of a profuse haemorrhage from a very large gastric ulcer which had not been 3 . recognized when the duodenal ulcer was oversewn. Sixteen other patients had excision of the ulcer with suture without mortality. Only one of the 0 total number of perforations proved to be a carcinoma of the stomach.

\section{Summary}

It would appear from this survey that $N$ primary partial gastrectomy is becoming a recog- N nized and rational procedure in the treatment of the perforated peptic ulcer.

Simple suture is adequate for patients under the age of 20 where medical treatment has received no trial, and where the history of peptic ulcer is less than six months.

The procedure for a perforated gastric ulcer over the age of 45 years is always a partial gastrec- 
tomy. Where the histology of a gastric ulcer is in doubt a frozen section biopsy should be taken before proceeding to definitive surgery (Fig. 2).

It is my pleasure to thank Dr. F. Avery Jones for access to his records, Dr. Richard Doll for personal communications, and Mr. A. G. Booker for the illustrations.

\section{BIBLIOGRAPHY}

ARMITAGE, G. (I953), Brit. med. F., March 14. AVERY JONES, F., et al. (I950), Ibid., January 28. AUCHINCLOSS, H. (1952), Ann. Surg., 135, No. I. DOLL, R. (1950), Brit. med. F., January 28. EMMETT, J. M., et al. (1953), Ann. Surg., 138, 320. FORGE, CLIFTON (1953), Ibid., 138, No. 3.

FORTY, FRANK (1946), Brit. med. F., May 25, p. 790.
GLEN, F., et al.

GRAHAM, R. R. (I946), 72, 802.

HENLEY, F. A. (1952), Brit. F. Surg., 40, No. 160.

HENLEY, F. A., (1953), Ann. R.C.S., 13, No. 3.

HESLOP, T. S. (1952), Brit. F. Surg., 40, No. 159.

ILLINGWORTH, C. F. N., et al. (I946), B.M.H., I, 787 .

IVY, GROSMAN and BACHRACH (I950), 'Peptic Ulcer.'

LASSEN, H. KRIEGER (I952), A.M.A. Arch. Surg., 65, No. 5.

LOWDON, A. G. R. (1952), Lancet, 1220.

MOORE, H. G., and HARKINS, H. (1952), 'The Bill roth I. Gastric Resection.'

NUBOER, J. F. (I95 I), Lancet, 952.

OLSON, H. B., and NORGORE, M. (1946), Ann. Surg., 124, 479

REA, C. E. (1952), Surg. St. Louis, 32, No. 4.

SPALOIZ, J. E. (1946), Lancet. i, 643.

TURNER, F. P. (1951), Surg. Gynae. Obst., 92, 28 I.

WALLENSTEN, S. (1952), Acta Chir. Scand., 104, Fase I.

WANGENSTREN, O. H. (1935), Minnesota Med., 18, 477.

WRIGHT, I.. T., and SCOTT, B. E. (I950), four. Pedia., 37, No. 6.

VISICK, A. HEDLEY (1946), Brit. med. F., p. 94 I.

\title{
¿ LARGE BOWEL OBSTRUCTION
}

\author{
By Guy Blackburn, M.Chir., F.R.C.S. \\ Surgeon, Guy's Hospital
}

The clinical picture of large gut obstruction is easily recognized in its classical and advanced form. Improvement in the results of treating it will come mainly from earlier diagnosis and acceptance of the fact that one of the triad of symptoms of colicky pain, distension and absolute constipation may often be sufficient to identify it. Vomiting, of course, is late and may merely signify secondary small intestine distension, because the ileo-caecal valve is no longer functioning efficiently. Alternatively, it may herald the onset of peritonitis from perforation or strangulation.

The most important maxim in dealing with potential cases of large gut obstruction is, firstly, to suspect it, when a patient has any one symptom of it, and secondly, to keep a close watch until the suspicion is dispelled or the diagnosis confirmed. Severe abdominal pain without diarrhoea is rarely of anything but surgical import and timely action in dealing with it may place a patient in surgical hands in good time to allow conservative measures to achieve relief, with subsequent elective surgery in optimum circumstances.

\section{Pathology}

Large gut obstruction occurs for the most part in elderly patients, the definition of elderly being in the seventh or eighth decades. This alone is the most important factor in prognosis, coupled with the fact that carcinoma of the colon is easily the commonest cause of the obstruction. This implies that occlusion is common and strangulation rare, the latter supervening in volvulus, band obstruction and rare examples of strangulated hernia. Umbilical hernia is the commonest of these, involving the transverse colon.

Local oedema and faecal impaction above an annular carcinoma of the pelvic colon convert a subacute into an acute obstruction. ${ }^{1}$ Distension above the growth may then result in perforation of the bowel, if the ileo-caecal valve is efficient enough to keep the loop ' closed' and not allow reflux of gas into the ileum. In these circumstances perforation of the pelvic colon or thinner and more distensible caecum (" pistol shot perforation') may dramatically complicate the picture, with dire results.

Carcinoma of the right half of the colon is more commonly papilliferous than annular and obstruction is correspondingly less frequent than on the left side ( $1: 7$ ) (Morgan). ${ }^{2}$ Rarely, in fact, is it the manner in which a patient with such a lesion presents, whereas IO-I 5 per cent. of patients with a ring carcinoma of the pelvic colon are first seen with large bowel obstruction. This may easily be confused with diverticulitis, though acute obstruc- 